\title{
СКРОМНЫЕ ДЕМОГРАФИЧЕСКИЕ РЕЗУЛЬТАТЫ ПРОНАТАЛИСТСКОЙ ПОЛИТИКИ В КОНТЕКСТЕ ДОЛГОВРЕМЕННОЙ ЭВОЛЮЦИИ РОЖДАЕМОСТИ В \\ РОССИИ . ЧАСТЬ 2
}

\section{СЕРГЕЙ ЗАХАРОВ}

\begin{abstract}
В российском экспертном сообществе и медийном пространстве получила распространение точка зрения о необыкновенном росте рождаемости в России, который свидетельствует о положительных результатах действия специальных мер по материальному стимулированию рождаемости, принятых государством после 2006 г.
\end{abstract}

В то же время имеют ли демографы сильные основания, чтобы поддерживать повыменный оптимизм, свойственный сегодня политикам и администраторам разного уровня? По мнению автора, некоторые положительные подвижки имеются, но значимость их совершенно недостаточна, чтобы смотреть на будущуее российской рождаемости и воспроизводство населения страны с оптимизмом.

В данной статье автор продолжает свои прежние исследования в области углубленного демографического анализа российской рождаемости с привлечением новейтих статистических данных за 2014 г. В статье дается общий обзор тенденций основных характеристик рождаемости за несколько десятилетий, а также развивается методологический аппарат анализа показателей рождаемости для реальных поколений с целью получения более надежных перспективных оченок.

Статья состоит из двух взаимосвязанньхх частей.

В первой части, представленной в предьдущем номере журнала, автор рассматривает показатели рождаемости для условных поколений (календарных лет) с учетом новейших изменений в структурных характеристиках российской модели рождаемости, произошедших за последние несколько десятилетий.

Во второй части статьи, представленной в данном номере журнала, речи идет о показателях рождаемости для реальных поколений женщин, фактическая и ожидаемая репродуктивная активность которых приходится на вторую половину XX-первые десятилетия XXI века.

Ключевые слова: рождаемость, очередность рождения, рождаемость условньх поколений, рождаемость реальных поколений, прогноз рождаемости, демографическая политика, пронаталистская семейная политика в России.

СЕРГЕЙ ВЛАДИМИРОВИЧ ЗАХАРОВ (szakharov@hse.ru), НАЦИОНАЛЬНЫЙ ИССЛЕДОВАТЕЛЬСКИЙ УНИВЕРСИТЕТ «ВЫСШАЯ ШКОЛА ЭКОНОМИКИ», РОССИЯ.

СТАТЬЯ ПОДГОТОВЛЕНА ПО РЕЗУЛЬТАТАМ ИССЛЕДОВАТЕЛЬСКОГО ПРОЕКТА «ТЕНДЕНЦИИ ДЕМОГРАФИЧЕСКОГО РАЗВИТИЯ РОССИИ В 2005-2015 ГГ. В КОНТЕКСТЕ ДОЛГОВРЕМЕННЫХ ДЕМОГРАФИЧЕСКИХ ТРЕНДОВ», ВЫПОЛНЕННОГО В РАМКАХ ПРОГРАММЫ ФУНДАМЕНТАЛЬНЫХ ИССЛЕДОВАНИЙ НИУ ВШЭ В 2016 Г.

СТАТЬЯ ПОСТУПИЛА В РЕДАКЦИЮ В АПРЕЛЕ 2016 Г. 


\section{4. РОЖДАЕМОСТЬ РЕАЛЬНЫХ ПОКОЛЕНИЙ: ЕСТЬ ЛИ ПОВОД ДЛЯ ОПТИМИЗМА?}

Как уже говорилось выше, в российском обществе точка зрения о необыкновенном росте рождаемости в России чрезвычайно популярна. Она якобы свидетельствует о положительных результатах действия специальных пронаталистских мер, принятых государством после 2006 г. В то же время многие демографы не склонны поддерживать повышенный оптимизм, свойственный сегодня политикам, администраторам разного уровня и широко растиражированный СМИ. Некоторые положительные подвижки имеются, но значимость их совершенно недостаточна, чтобы смотреть на будущее российской рождаемости с оптимизмом.

Больших восторгов не вызывает главный и единственно бесспорный критерий изменения уровня рождаемости - динамика показателей итоговой рождаемости женских поколений по году рождения.

Итоговая рождаемость для поколений 1970-х и 1980-х годов рождения, повидимому, будет ниже итоговой рождаемости у их матерей, родившихся в 1950-х и 1960-х годах, что свидетельствует о продолжении исторической тенденции снижения рождаемости, которую пока не удается переломить (рисунок 9). С другой стороны, сближение уровней рождаемости материнских и дочерних поколений - исторический факт, свидетельствующий, в частности, о завершенности демографического перехода к рождаемости, регулируемой на индивидуальном и внутрисемейном уровне, и утверждения двухдетной семьи в качестве желанной и наиболее распространенной модели [Демографическая модернизация... 2006: 153-175]. Если принять историческую вариацию длины поколения в интервале от 25 до 30 лет $^{1}$, то россиянки, родившиеся в 1970-х - 1980-х годах и завершающие сегодня деторождение, родили в среднем на $10 \%$ меньше детей, чем их «матери» 1940-х-1950-х годов рождения. Для сравнения, их «бабушки», родившиеся в первых десятилетиях XX века, произвели на свет наполовину меньше детей, чем их «прабабушки» - женщины, родившиеся на рубеже XIX и XX веков (рисунок 10).

Рассмотрим более подробно перспективы стабилизации и возможного роста итоговых показателей рождаемости для реальных поколений женщин в России с учетом окончательных данных за 2014 г. (самых последних полных данных, доступных к моменту завершения данной статьи).

\footnotetext{
${ }^{1}$ Длина поколения в демографии - интервал времени между появлением поколений родителей и детей. Если пренебречь влиянием смертности женщин в интервале репродуктивных возрастов, он приближенно равен среднему возрасту матери при рождении дочерей всех порядков рождения и находится обычно в интервале от 25 до 30 лет.
} 


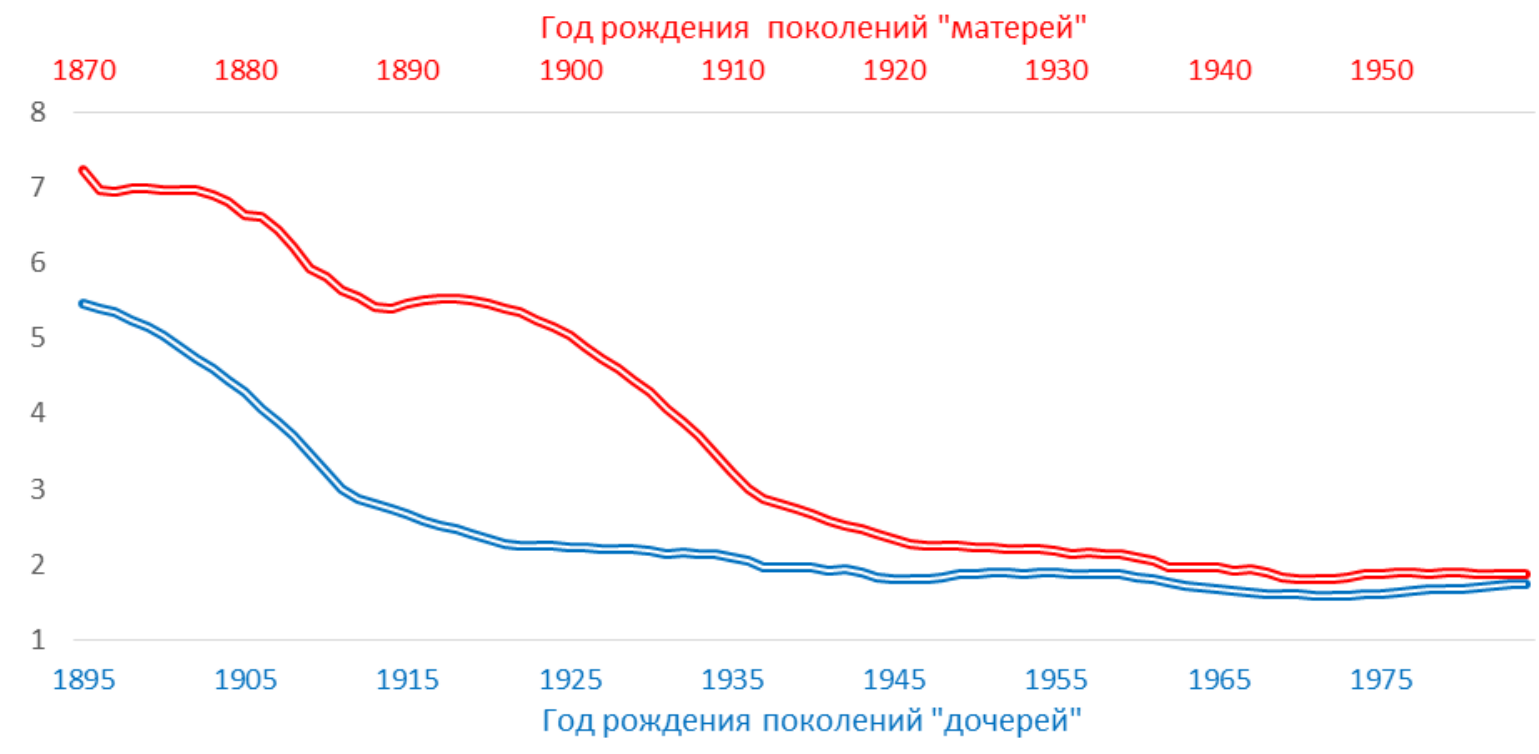

\section{Рисунок 9. Итоговое число родившихся на одну женщину в поколениях "матерей"} 1870-1960 и их «дочерей» 1895-1985 годов рождения

Источник: Оченки, полученные автором в результате реконструкиии исторических динамических рядов показателей итоговой рождаемости. См.: [Демографическая модернизация... 2006: 155-157; 170-171].

Примечание: Для поколений 1965 года и моложе - ожидаемая величина при сохранении возрастных коэффициентов рождаемости 2014 г.

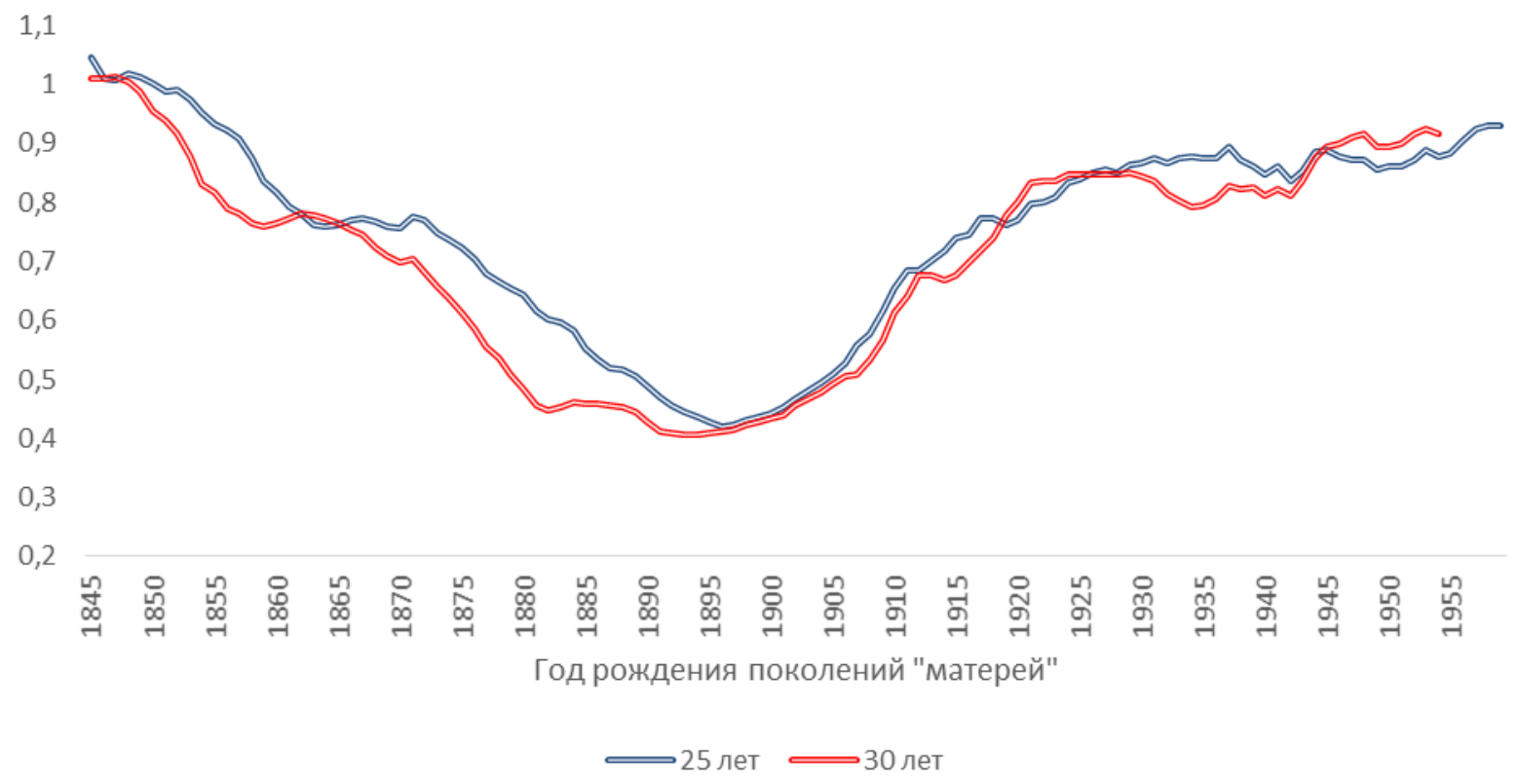

Рисунок 10. Отношение значений итоговой рождаемости поколений «дочерей» к значениям у их "матерей" при длине поколения, принятой 25 и 30 лет, Россия

Источник: Оценки, полученные автором в результате реконструкции исторических динамических рядов показателей итоговой рождаемости См.: [Демографическая модернизация... 2006: 155-157; 170-171]. 
Напомним, что методология получения показателей рождаемости для реальных поколений включает преобразование данных текущего учета родившихся по очередности рождения, распределенных по однолетним возрастным группам, в распределения рождений для реальных поколений женщин по году рождения, которые затем используются в качестве основы для построения специальных вероятностных таблиц рождаемости, дифференцированных по очередности рождения. Техника построения таких таблиц аналогична таблицам для условных поколений (календарных лет), о чем шла речь выше. В результате построения таблиц для реальных поколений мы также получаем динамические ряды вероятностей увеличения семьи для каждого возраста, дифференцированные по очередности рождения, и обобщающие характеристики рождаемости (итоговая величина рождаемости для каждой очередности рождения, средний возраст матери при рождении ребенка каждой очередности, распределение женщин по числу когда-либо рожденных детей и некоторые другие). В отличие от аналогичных табличных показателей, рассчитанных для условных поколений, характеристики из таблиц для реальных поколений будут максимально свободны от влияния изменений в календаре рождений, происходящих от поколения к поколению. Имеется, однако, проблема, связанная с оценкой итоговой рождаемости и итоговых вероятностей увеличения семьи для каждой очередности рождения для когорт, которые в силу своего возраста еще не завершили репродуктивную биографию.

На рисунке 11 представлены кумулятивные коэффициенты рождаемости для средних представителей женских поколений, родившихся в 1940-1990 гг., к возрасту 20, 25 , $30,35,40$ и 50 лет (накопленная рождаемость к 50 годам может считаться итоговой рождаемостью поколения), полученные на основе когортной трансформации фактически зафиксированных возрастных коэффициентов рождаемости за период с 1959 по 2014 г.

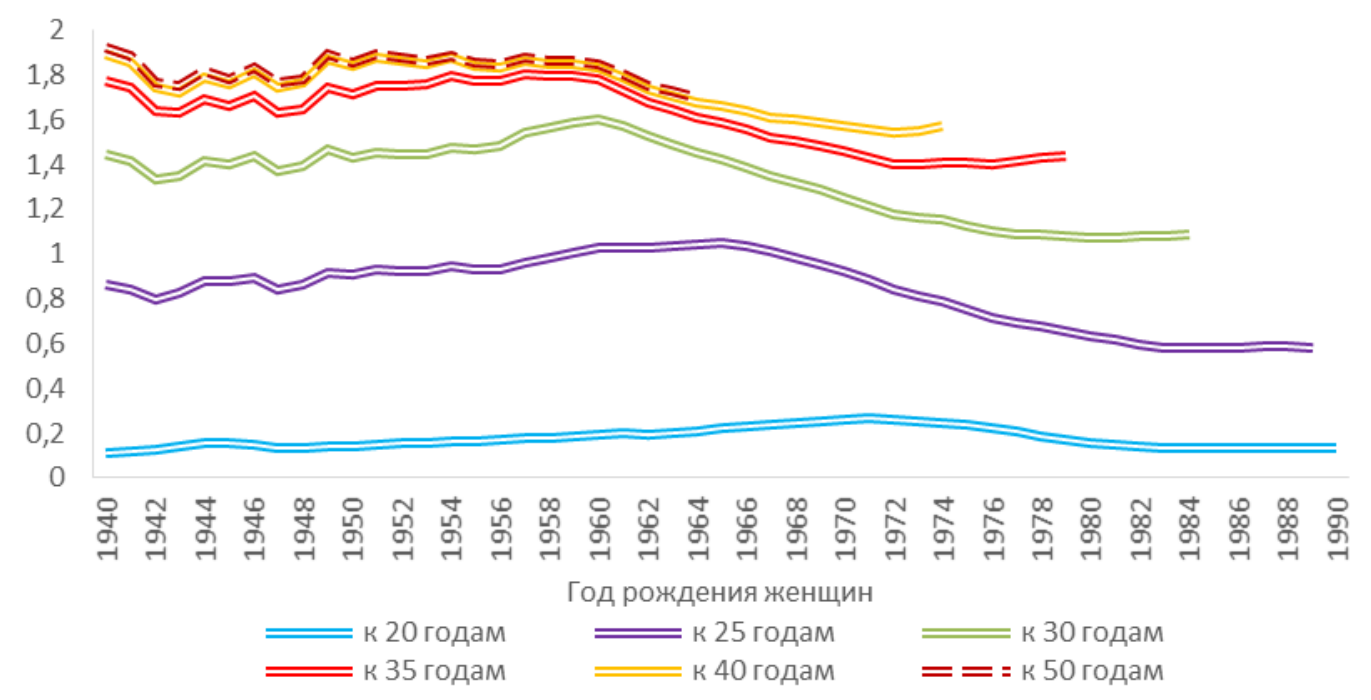

Рисунок 11. Кумулятивные коэффициенты рождаемости к указанным возрастам (последние использованные данные относятся к 2014 г.), Россия, однолетние женские поколения 1940-1990 годов рождения, число рождений на 1 женщину

Источник: Расчеты автора на основе [HFD 2016] и неопубликованных данных Росстата. 
Накопленная рождаемость к возрасту 25 лет у поколений, родившихся в середине 1980-х годов, на 40\% ниже, чем у поколений второй половины 1960-х годов (0,6 рождений в среднем на одну женщину против 1,0$)$. Никаких признаков роста у самых молодых поколений в молодом возрасте мы не наблюдаем.

Поколения, родившиеся в конце 1970-х - начале 1980-х годов и достигшие к 2015 г. 30 и 35 лет, демонстрируют едва заметное оживление показателей накопленной рождаемости, свидетельствующее о некоторой стабилизации или даже о едва заметных признаках роста. В то же время накопленная рождаемость к сопоставимому возрасту у этих поколений более чем на 20-30\% ниже, чем у поколений россиянок, родившихся в 1960-х годах: к 30 годам накопленная рождаемость у когорты 1979 г. 1,08 рождения в расчете на одну женщину против 1,60 у когорты 1960 г.; к возрасту 35 лет для тех же когорт соответственно: 1,44 против 1,78.

Близкий к итоговой рождаемости поколений показатель кумулятивной рождаемости к возрасту 40 лет, непрерывно снижавшийся у женщин, родившихся в конце 1950-х - начале 1970-х годов, в последние несколько лет обнаружил едва заметные признаки роста, однако его величина, равная 1,57 для когорты 1974 г. как минимум на 0,2 рождения ниже, чем была у их матерей, родившихся в конце 1940-х - начале 1950-х годов.

Смогут ли поколения 1980-х годов своими показателями итоговой рождаемости вернуться к уровню, характерному для их матерей - поколений 1950-х - 1960-х годов (1,81,9 рождения на одну женщину)? Скорее всего, нет. Даже уровень 1,7 рождения на одну женщину будет для них сверхоптимистическим прогнозом (см. рисунок 12, на котором представлено отклонение кумулятивных возрастных коэффициентов рождаемости поколений 1965-1985 годов от коэффициентов для поколения 1960 года).

Ожидаемый итоговый результат поколений 1980-х годов - 1,6 рождения или чуть более, в среднем, на одну женщину при условии, что тенденции последних лет сохранят свою силу в ближайшее десятилетие. Это будет означать остановку многолетнего снижения рождаемости в России и соответственно снижения числа детей в российских семьях, но на уровне слишком низком, чтобы выйти из суженного режима замещения поколений. Надеяться на то, что каждое новое поколение детей в численном отношении будет хотя бы приблизительно соответствовать родительскому поколению, пока нет оснований. Дадут ли такие основания поколения 1990-х годов, говорить пока слишком рано - большинство из них еще не достигло возраста максимальной интенсивности деторождения. 


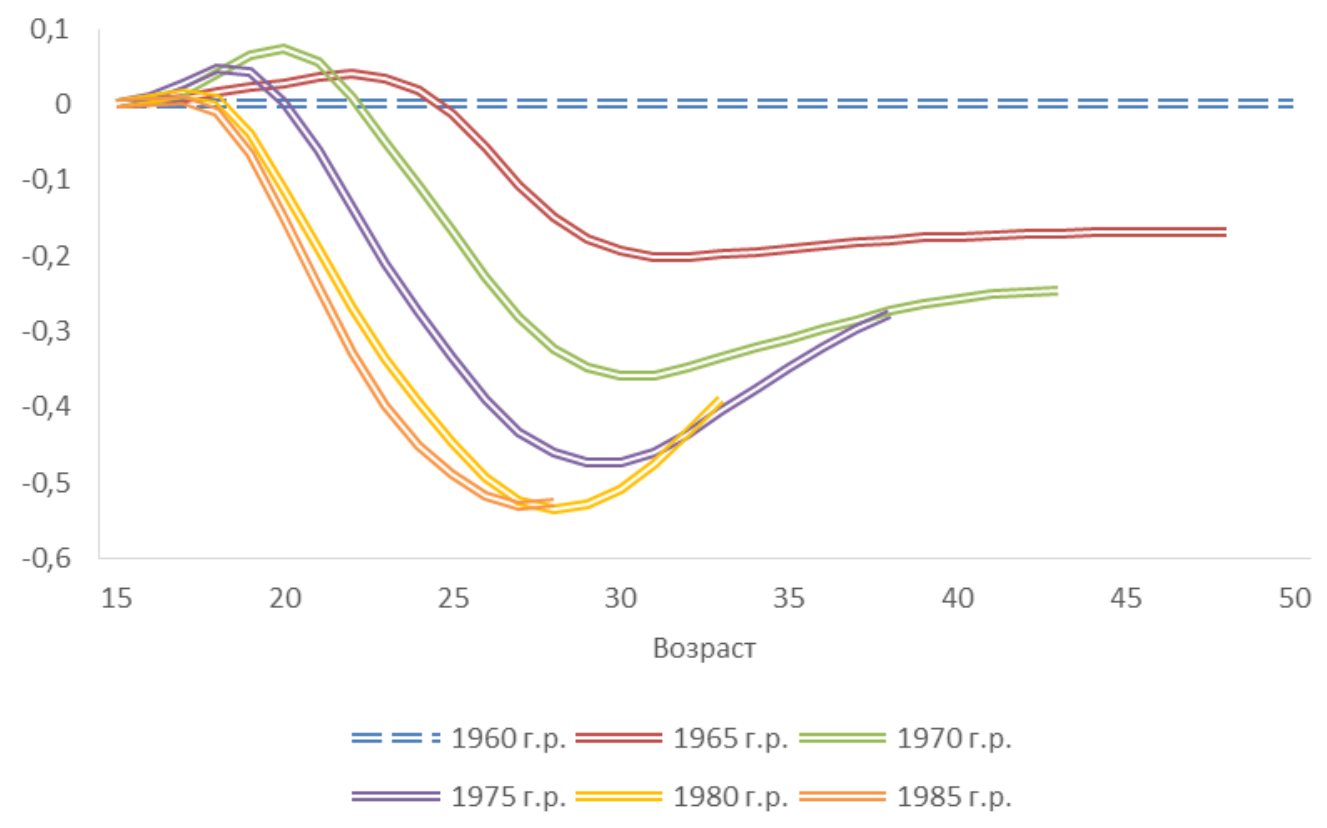

\section{Рисунок 12. Отличия значений возрастных кумулятивных коэффициентов рождаемости для женщин 1965, 1970, 1975, 1980 и 1985 годов рождения от значений для поколения 1960 года (последние использованные данные относятся к 2014 г.). Число рождений на одну женщину}

Источник: Расчеты автора на основе [HFD 2016] и неопубликованных данных Росстата.

Специальные таблицы рождаемости, построенные с учетом очередности рождения для реальных поколений, позволяют оценить накопленные значения вероятностей увеличения семьи к тому или иному возрасту (cumulative Parity Progression Ratios by age). Эти показатели аналогичны по своей сути тем, о которых шла речь выше применительно к таблицам рождаемости для условных поколений, т.е. они также представляют собой накопленную долю женщин, родивших очередного ребенка, среди тех, кто родил к фиксированному возрасту на одного ребенка меньше: первого ребенка среди ни разу не рожавших, второго среди родивших первого и т.д. Но если в случае условных поколений мы трактовали вероятности увеличения семьи как ожидаемые показатели при сохранении интенсивности рождаемости текущего года, то для реальных поколений, достигших того или иного возраста, вероятности увеличения семьи к данному возрасту отражают долю женщин, фактически реализовавших возможность перехода к состоянию с числом рождений на одно больше. Так, вероятность увеличения семьи для ни разу не рожавших женщин (PPR $0 \rightarrow 1)$ показывает долю женщин из некоторого поколения, фактически родивших первого ребенка к тому или иному возрасту (рисунок 13). Кумулятивный показатель к возрасту 50 лет позволяет оценить окончательную долю бездетных женщин, для чего нужно вычесть из единицы (теоретическое значение, говорящее о полном отсутствии детей) полученную по таблицам величину вероятности рождения для первого ребенка. К примеру, поколение 1960 г. завершило свою репродуктивную биографию с вероятностью рождения первого ребенка равным 0,95, что свидетельствует о 5\%-ном уровне окончательной бездетности (в расчет принимаются только живорождения и не учитывается смертность детей). Для женщин 1970 года рождения, перешагнувших 40- 
летний возрастной рубеж, ожидаемая величина составляет 0,92 (8\% останутся окончательно бездетными). Полученная нами оценка накопленной вероятности первого рождения к 35-летнему возрасту, равная 0,83 для самого молодого поколения, достигшего этого возрастного рубежа к 2015 г. (женщин 1979 года рождения), позволяют утверждать, что в России сохраняется тренд увеличения доли ни разу не рожавших женщин. Значения показателя для 35-летних женщин слабо в меньшую сторону отличаются от значений для 50-летних женщин, что дает нам сильные основания прогнозировать долю окончательной бездетности для женщин, родившихся во второй половине 1970-х годов, на уровне 12-14\%. Сходные оценки ожидаемой доли окончательной бездетности для тех же поколений были получены С.С. Бирюковой и А.О. Тындик в результате построения функции дожития методом Каплан-Майера на основе данных переписи населения 2010 г. [Biryukova, Tyndik 2015].

За время, равное периоду репродуктивной деятельности пятнадцати однолетних поколений, распространенность бездетности в России увеличилась в 2 раза. Как уже говорилось, пронаталистская государственная политика никак не сказалась на этой тенденции. Важно подчеркнуть, что при столь значительном росте пропорции женщин, не родивших за свою жизнь хотя бы одного ребенка, усилия, направленные на стимулирование повторных рождений, могут не привести к желаемому результату - росту средней величины итоговой рождаемости поколений до уровня, позволяющего обеспечить хотя бы простое замещение поколений, что и было показано выше. Увеличение вероятности рождения детей второй и третьей очередностей (рисунки 14 и 15) не настолько значительно, чтобы скомпенсировать кумулятивный эффект от существенного снижения вероятности первых рождений.

Демографическая политика после 2007 г., вероятно, сказалась в положительную сторону на вероятности вторых и третьих рождений в стране. Интересно, что политика, задуманная как политика «второго ребенка», принесла сопоставимый результат в отношении прироста вероятности появления на свет третьих детей (рисунок 15). Имеются даже некоторые признаки роста вероятности рождения четвертых и последующих детей в раннем возрасте (рисунок 16).

К 30 годам среди тех, кто родил к этому возрасту первого ребенка, второго ребенка родили 43\% представительниц когорты 1984 года рождения (самой молодой когорты, достигнувшей данного возраста). По сравнению с минимальным значением, продемонстрированным когортой 1976 года рождения (36\%), прирост составил 7 п.п. К 35 годам этот показатель составил 55\% у самой молодой когорты, достигшей этого возраста (когорта 1979 года рождения), против исторического минимума в 49\%, (когорта 1971 года рождения), т.е. прирост составил 6 п.п. Вероятность рождения третьего ребенка к возрасту 30 лет для самой молодой когорты находится на уровне 18\%, что на 3 п.п. выше исторического для России минимума. К 35 годам для самых молодых поколений вероятность третьего рождения находится на уровне $24 \%$, что означает прирост на 5 п.п. по сравнению с минимальными значениями. Последние оценки для вероятности третьих рождений свидетельствуют об их приближении к максимальным значениям, достигнутым представителями поколений 1950-х годов рождения, репродуктивная активность которых пришлась также на период активизации демографической политики в 1980-х годах. В то же 
время вероятность вторых рождений сегодня еще очень далеко отстоит от значений, достигнутых в 1980-е годы поколениями 1950-1960-х годов рождения.

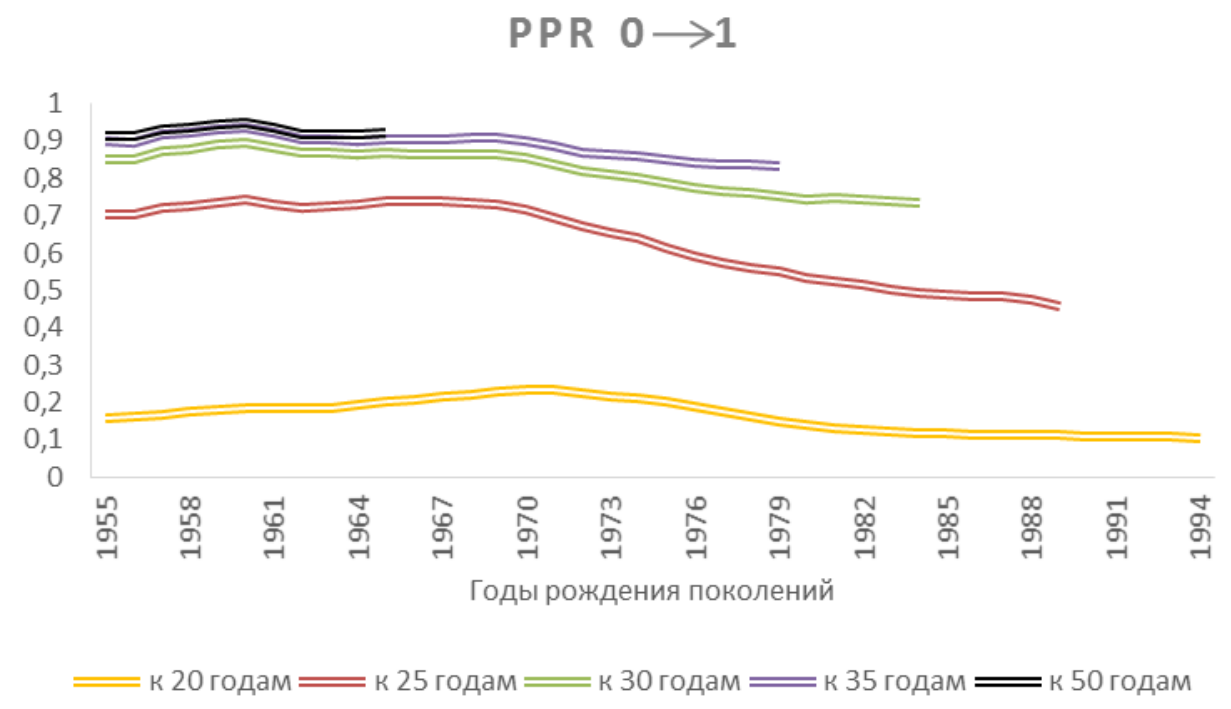

Рисунок 13. Кумулятивные значения вероятности рождения первого ребенка к указанным возрастам (последние данные, приятые в расчет, относятся к 2014 г.), Россия, женские поколения 1955-1994 годов рождения

Источник: Расчеты автора на основе [HFD 2016] и неопубликованных данных Росстата.

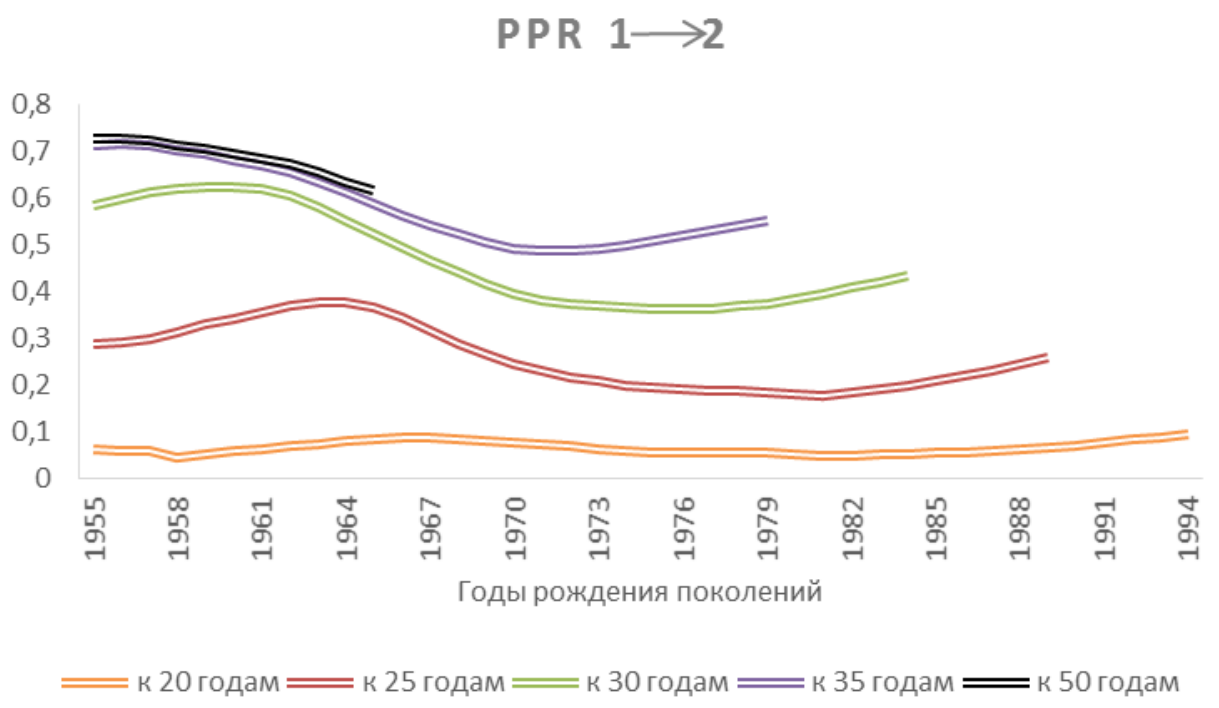

Рисунок 14. Кумулятивные значения вероятности рождения второго ребенка к указанным возрастам (последние данные, приятые в расчет, относятся к 2014 г.), Россия, женские поколения 1955-1990 годов рождения

Источник: Расчеты автора на основе [HFD 2016] и неопубликованных данных Росстата. 
PPR $2 \longrightarrow 3$

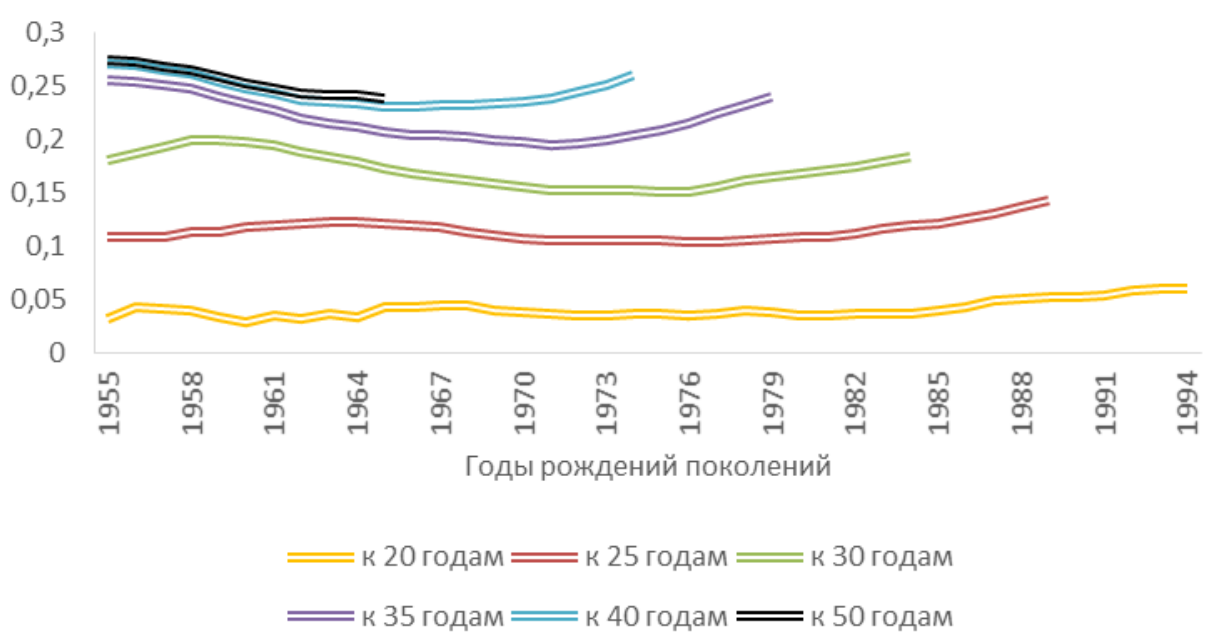

Рисунок 15. Кумулятивные значения вероятности рождения третьего ребенка к указанным возрастам (последние данные, приятые в расчет, относятся к 2012 г.), Россия, женские поколения 1955-1990 годов рождения

Источник: Расчеты автора на основе [HFD 2016] и неопубликованных данных Росстата.

$$
\text { PPR } 3 \longrightarrow 4
$$

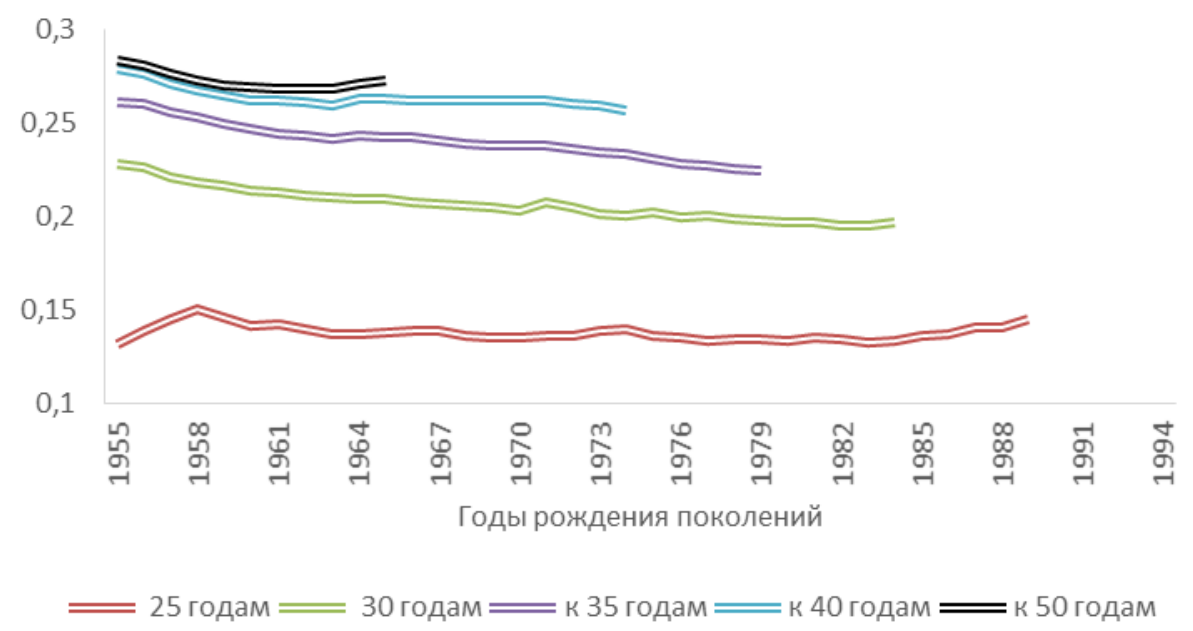

Рисунок 16. Кумулятивные значения вероятности рождения четвертого ребенка к указанным возрастам (последние данные, приятые в расчет, относятся к 2012 г.), Россия, женские поколения 1955-1990 годов рождения

Источник: Расчеты автора на основе [HFD 2016] и неопубликованных данных Росстата.

Затруднительно объяснить существенный рост вероятности третьих рождений только лишь усилением материальных стимулов, на которые обращает повышенное 
внимание российская официальная пропаганда ${ }^{2}$. Это феномен заслуживает более пристального внимания исследователей. Как уже указывалось мною ранее [Население России... 2014: 144-147], возможности объяснения выходят за рамки собственно демографического анализа и, видимо, связаны с социально-экономической, региональной и этнической неоднородностью российского общества. Не исключено также, что миграционная привлекательность России усиливает социокультурную неоднородность ее населения, в том числе и в отношении реализуемых репродуктивных стратегий. В то же время нельзя не обратить внимание, что складывающаяся ситуация с повторными рождениями во многом напоминает ситуацию, которую пережила Россия в 1980-х годах, когда вслед за принятием новых мер семейной политики также последовало ускоренное формирование семей за счет вторых и третьих рождений, которое, однако, не привело к значимому увеличению итоговой рождаемости поколений. Станем ли мы свидетелями повторения опыта 1980-х годов, или нас ожидает иная, более обнадеживающая ситуация, покажет будущее.

Представления об итоговой величине рождаемости для реальных поколений, еще не вышедших из репродуктивного возраста, можно получить, если каким-нибудь образом «достроить» фактически рожденные к моменту наблюдения числа детей для каждого поколения, некоторым образом полученными для них ожидаемыми числами «еще пока не рожденных детей». На международном уровне принят подход, при котором производится суммирование фактически рожденного к моменту наблюдения числа детей для каждого поколения женщин и гипотетического числа детей, которое можно ожидать, если в последующих возрастах средняя женщина из данного поколения будет иметь такую же рождаемость, какую продемонстрировали в год наблюдения женщины, достигшие этих возрастов. При таком подходе для поколения женщин, которым в год наблюдения исполнилось 15 лет, оценка итоговой рождаемости полностью базируется на «ожидаемой» компоненте и численно совпадает с обычным коэффициентом суммарной рождаемости для условных поколений, т.е. это - совершенно условная величина. Чем старше поколение, тем вклад «ожидаемой» компоненты меньше, и в оценке итоговой величины рождаемости все более значимую роль играет уже реализованная, фактическая рождаемость.

Если производить регулярные оценки, учитывающие меняющиеся год от года возрастные коэффициенты рождаемости, то можно получить динамическую картину последовательных изменений в оценках и «фактической», и «ожидаемой» компонент итоговой рождаемости для одного и того же поколения, а следовательно, и их суммарного

\footnotetext{
${ }^{2}$ К примеру, приходится часто слышать о положительной роли специального ежемесячного пособия в размере прожиточного минимума, выплачиваемого при рождении третьего и последующих детей до достижения ими 3-х летнего возраста в более чем 50 регионах РФ из ежегодно утверждаемого правительством списка регионов, в которых была зафиксирована величина коэффициента суммарной рождаемости ниже среднероссийского уровня или с естественной или миграционной убылью населения (эта мера была введена на основании Указа Президента РФ от 7 мая 2012 г. №606 «О мерах по реализации демографической политики Российской Федерации» и регулируется Правилами, утвержденными Постановлением правительства №1112 от 31 октября 2012 г. с последующими изменениями). Размер пособия вполне весом: в 2014 г. он варьировался от 4,8 тыс. руб. в Тамбовской области до 13,7 тыс. в Камчатском крае. Вполне вероятно, что какое-то влияние на расширение многодетности в России сейчас такая мера оказывает. Однако с ней никак нельзя связать тренд повышения вероятности третьего рождения, начавшийся задолго до 2013 г., когда эта мера политики была введена.
} 
значения. В последние десятилетия в развитых странах и России происходит увеличение рождаемости у женщин старше 25 и даже старше 35 лет, и до тех пор, пока наблюдается это увеличение, ожидаемые оценки итоговой рождаемости будут пересматриваться в сторону повышения не только для самых молодых поколений, но и для представительниц старших когорт с растущим вкладом поздней рождаемости.

В докладах ИДЕМ НИУ ВШЭ «Население России» на протяжении уже многих лет представлялись рассчитанные мной ежегодные оценки ожидаемой итоговой рождаемости российских поколений, основанных на подходе, принятом на международном уровне и учитывающем данные о когортной рождаемости за самый последний год, обеспеченный соответствующими данными ${ }^{3}$.

Посмотрим, какие можно было бы сделать оценки итоговой рождаемости для послевоенных поколений, опираясь на ретроспективные данные, ограниченные 1999 г. (год исторически минимальной величины коэффициента суммарной рождаемости), и сравним их с оценками, полученными для тех же поколений на основе последних имеющихся данных за 2014 г. (таблица 10). Кроме того, чтобы оценить особо значимый вклад роста рождаемости после 2006 г. (т.е. после того, как были введены в действие новые меры демографической политики), в таблице воспроизведены оценки ожидаемой итоговой рождаемости, выполненные мною ранее с опорой на данные за 2006 г.

Таблица 10. Фактическая и перспективная рождаемость реальных поколений в России, женщины 1955-1989 годов рождения

\begin{tabular}{|c|c|c|c|c|c|c|c|}
\hline \multirow[b]{2}{*}{$\begin{array}{l}\text { Годы } \\
\text { рождения } \\
\text { женщин }\end{array}$} & \multicolumn{2}{|c|}{$\begin{array}{c}\text { Итоговое число } \\
\text { рождений }\end{array}$} & \multicolumn{3}{|c|}{ Оценка на основе данных 2014 г. } & \multirow{2}{*}{$\begin{array}{c}\text { Разница } \\
\text { между } \\
\text { оценками } \\
1999 \text { и } \\
2013 \text { г. }\end{array}$} & \multirow{2}{*}{$\begin{array}{c}\text { Разница } \\
\text { между } \\
\text { оценками } \\
2006 \text { и } \\
2013 \text { г. }\end{array}$} \\
\hline & $\begin{array}{c}\text { оценка } \\
\text { на } \\
\text { основе } \\
\text { данных } \\
1999 \text { г. }\end{array}$ & $\begin{array}{c}\text { оценка на } \\
\text { основе } \\
\text { данных } \\
2006 \text { г. }\end{array}$ & $\begin{array}{c}\text { фактически } \\
\text { рождено к } \\
2015 \text { г., } \\
\text { детей на } \\
\text { одну } \\
\text { женщину }\end{array}$ & $\begin{array}{c}\text { ожидается } \\
\text { рождений } \\
\text { дополнительно } \\
\text { к уже } \\
\text { рожденным }\end{array}$ & $\begin{array}{c}\text { итоговое } \\
\text { число } \\
\text { рождений }\end{array}$ & & \\
\hline $1955-1959$ & 1,88 & 1,88 & 1,88 & 0,00 & 1,88 & 0,00 & 0,00 \\
\hline $1960-1964$ & 1,75 & 1,76 & 1,76 & 0,00 & 1,76 & 0,01 & 0,00 \\
\hline $1965-1969$ & 1,58 & 1,63 & 1,64 & 0,00 & 1,64 & 0,06 & 0,01 \\
\hline $1970-1974$ & 1,40 & 1,52 & 1,58 & 0,02 & 1,60 & 0,20 & 0,08 \\
\hline $1975-1979$ & 1,23 & 1,43 & 1,52 & 0,12 & 1,64 & 0,41 & 0,21 \\
\hline $1980-1984$ & 1,16 & 1,33 & 1,30 & 0,42 & 1,72 & 0,56 & 0,39 \\
\hline 1985-1989 & - & - & 0,86 & 0,90 & 1,76 & - & - \\
\hline
\end{tabular}

Источник: Расчеты автора, основанные на неопубликованных данных Росстата: переписей населения 1979, 1989 г. (распределений женщин по числу рожденных детей для однолетних возрастных групп) - и возрастных коэффициентах рождаемости для однолетних возрастных групп в 1979-2014 г2.

Очевидно, что итоговая рождаемость для женских когорт второй половины 1950-х годов рождения ( 1,88 ребенка на одну женщину) не менялась - эти поколения уже в первой половине 2000-х годов были близки к завершению репродуктивной карьеры, а в 2010 г. из него уже вышли. Показатели для поколений, родившихся в первой половине 1960-х годов, изменились по сравнению с оценкой 1999 г. в сторону увеличения едва заметно - 1,76

\footnotetext{
${ }^{3}$ Впервые такие оценки были нами опубликованы в 2004 г. [Население России... 2004: 55].
} 
против 1,75, а изменения, произошедшие после 2006 г., выходят за пределы принятой нами значимости индикатора (два знака после запятой). Рост рождаемости, отмеченный в последнее десятилетие, не прошел бесследно для поколений женщин, рожденных во второй половине 1960-х годов: их итоговая рождаемость перешагнула отметку 1,6 ребенка (1,64 против 1,58 в 1999 г.). Правда, прирост рождений в 2007-2014 гг. для них едва значим - 0,01 в расчете на одну женщину.

Более значимо изменились ожидаемые показатели рождаемости для когорт, родившихся в 1970-х годах: по сравнению с оценками, исходившими из фактической накопленной и ожидаемой рождаемости к 2000 г., более поздние оценки дают прирост 0,20,4 ребенка в расчете на одну женщину. За один только 2007 г. эти поколения «добрали» к величине итоговой рождаемости 0,03-0,07 ребенка, а в сумме за 2007-2014 гг. - 0,1-0,2. Легко подсчитать, что если тенденция к увеличению рождаемости в возрастах старше 30 лет сохранится, то поколения женщин, родившиеся в 1970-х годах, будут иметь в итоге, в среднем, 1,62 рождения. К сожалению, эти поколения уже не имеют шансов перешагнуть за указанный порог, поскольку их представительницы неумолимо приближаются к 40летнему юбилею или уже его отпраздновали. Итоговая рождаемость поколений 1970-х годов, без сомнений, будет ниже, чем у предшествующих поколений.

Поколения, родившиеся в 1980-х годах, возможно, завершат свою репродуктивную биографию с несколько большей рождаемостью, чем поколения 1970-х. С учетом наблюдаемых сегодня тенденций у них имеются шансы достигнуть в среднем 1,75 рождений на одну женщину. Если такая величина будет достигнута, то это будет означать, что долговременное снижение итоговой рождаемости в России остановится, и можно будет даже надеяться на ее рост. С такими характеристиками Россия будет не сильно отличаться от прогнозируемых в среднем для Европы показателей рождаемости для условных и реальных поколений.

Итак, при фиксированных возрастных коэффициентах рождаемости на уровне 2014 г. для поколений, достигших 25 лет и старше к 2015 г., перспектива, как минимум, стабилизации итоговой рождаемости реальных поколений в России на уровне 1,7-1,8 выглядит вполне обоснованной.

С целью проконтролировать полученный результат мы прибегли к альтернативному методу перспективной оценки итоговой рождаемости для женских поколений, которые перешагнули за 25-летний возраст. С учетом сегодняшней российской возрастной модели рождаемости все женщины старше 25 лет достигли или уже преодолели пиковое значение интенсивности деторождения.

Предлагаемый ниже метод основан на экстраполяции возрастных значений вероятностей рождения очередного ребенка для реальных поколений, базирующейся на моделировании темпов снижении возрастных значений вероятностей родить ребенка для условных поколений (для календарных периодов) раздельно для каждой очередности рождения за пределами возраста, в котором были достигнуты пиковые значения. Значения вероятностей родить очередного ребенка взяты из специальных таблиц рождаемости для условных поколений, рассмотренных выше. Следует отметить, что в условных поколениях кривая, описывающая темпы изменений вероятностей рождения ребенка каждой 
очередности для женщин после 25 лет, демонстрирует достаточно высокую устойчивость во времени (рисунок 17).

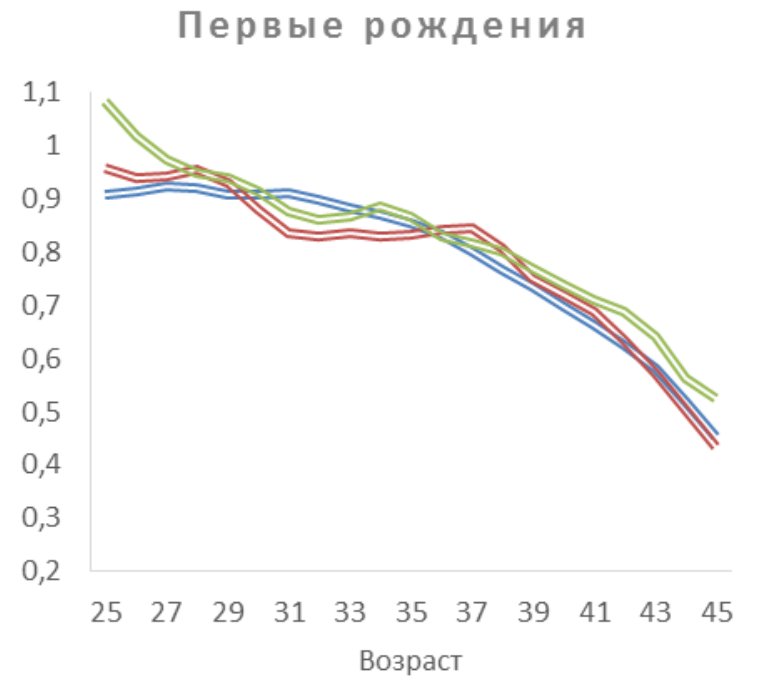

Третьи рождения

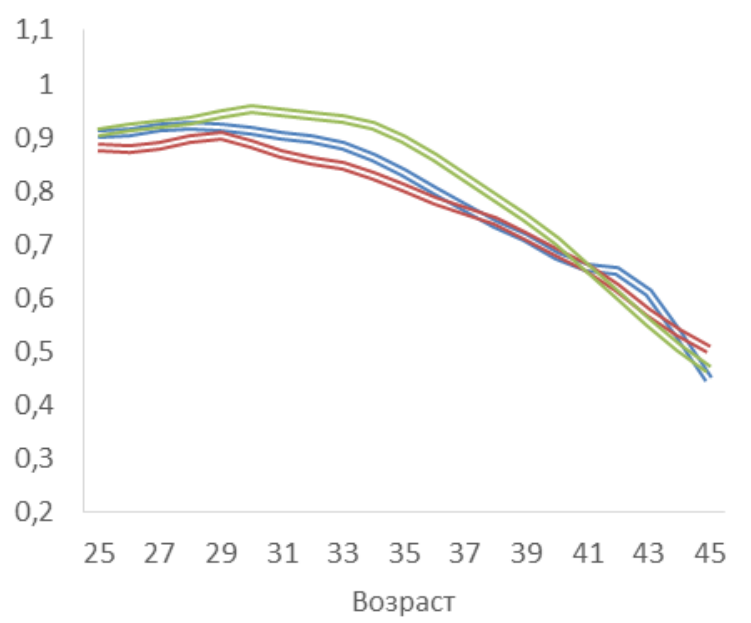

Вторые рождения

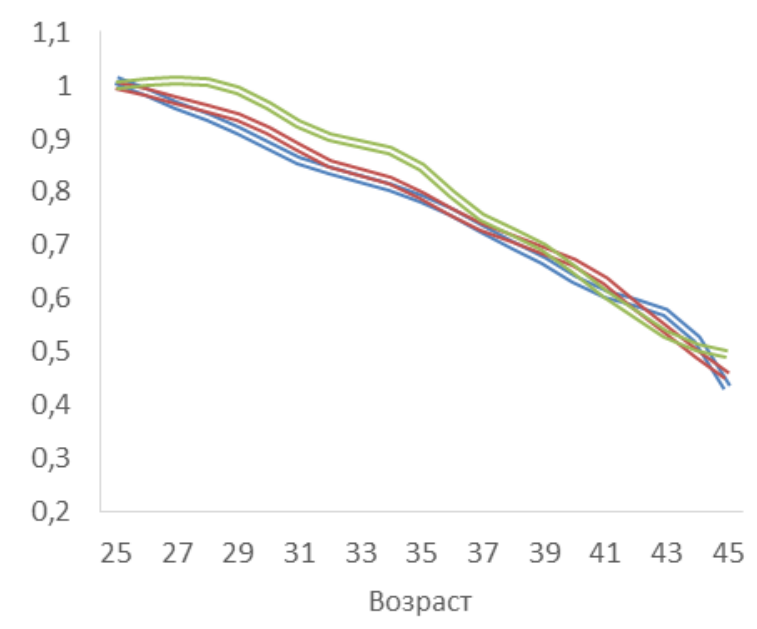

Четвертые рождения

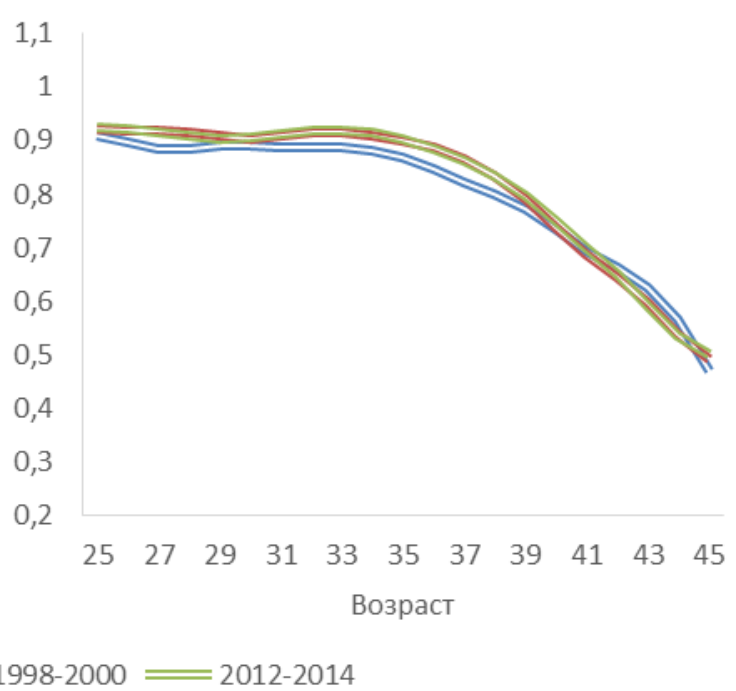

\section{Рисунок 17. Темпы снижения вероятностей родить первого, второго, третьего и четвертого ребенка на возрастном интервале 25-45 лет, Россия, среднегодовые значения для периодов 1988-1990, 1998-2000, 2012-2014 гг.}

Источник: Расчеты автора на основе неопубликованных данных Росстата.

Устойчивость возрастной кривой снижения вероятностей очередного рождения весьма наглядно демонстрируется при сравнении усредненных значений для трехлетних периодов с различным уровнем и возрастным профилем рождаемости (рисунок 17): 19881990 гг. (последние годы советского времени с относительно высоким уровнем и «молодым» профилем рождаемости), 1998-2000 гг. (период с историческим минимумом уровня рождаемости в самом начале трансформации ее возрастного профиля), 2012-2014 гг. (последние данные с повышенной интенсивностью рождений и возрастным профилем в стадии активного старения). Можно предположить, что и в ближайшем десятилетии 
функция относительных изменений с возрастом вероятностей рождения очередного ребенка принципиальным образом не изменится.

Было произведено сглаживание представленных выше кривых для периода 2012 2014 гг. раздельно для каждой очередности сплайнами четвертого-пятого порядков (стандартные функции сглаживания, предлагаемые программой MS Excel), которые практически идеально аппроксимируют среднегодовые кривые для данного трехлетия $\left(\mathrm{R}^{2}\right.$ для первых рождений - 0,95, для вторых и последующих - 0,99). После получения модельной кривой изменения возрастных функций вероятностей очередного рождения они были использованы для экстраполяции значений для реальных поколений на отрезке возрастного интервала деторождения от возраста, достигнутого в 2014 г. (25 лет и старше), и до 50 лет. Фактические значения вероятностей, дополненные экстраполированными значениями, были использованы для построения полных специальных таблиц рождаемости по очередности рождения для реальных поколений. Преимущество описанного подхода как раз и состоит в том, что мы получаем возможность построить полные специальные таблицы рождаемости, а следовательно, получить перспективные оценки таких важных характеристик, как итоговые вероятности увеличения семьи для каждой очередности рождения, средний возраст матери при рождении очередного ребенка, интервалы между рождениями детей и др.

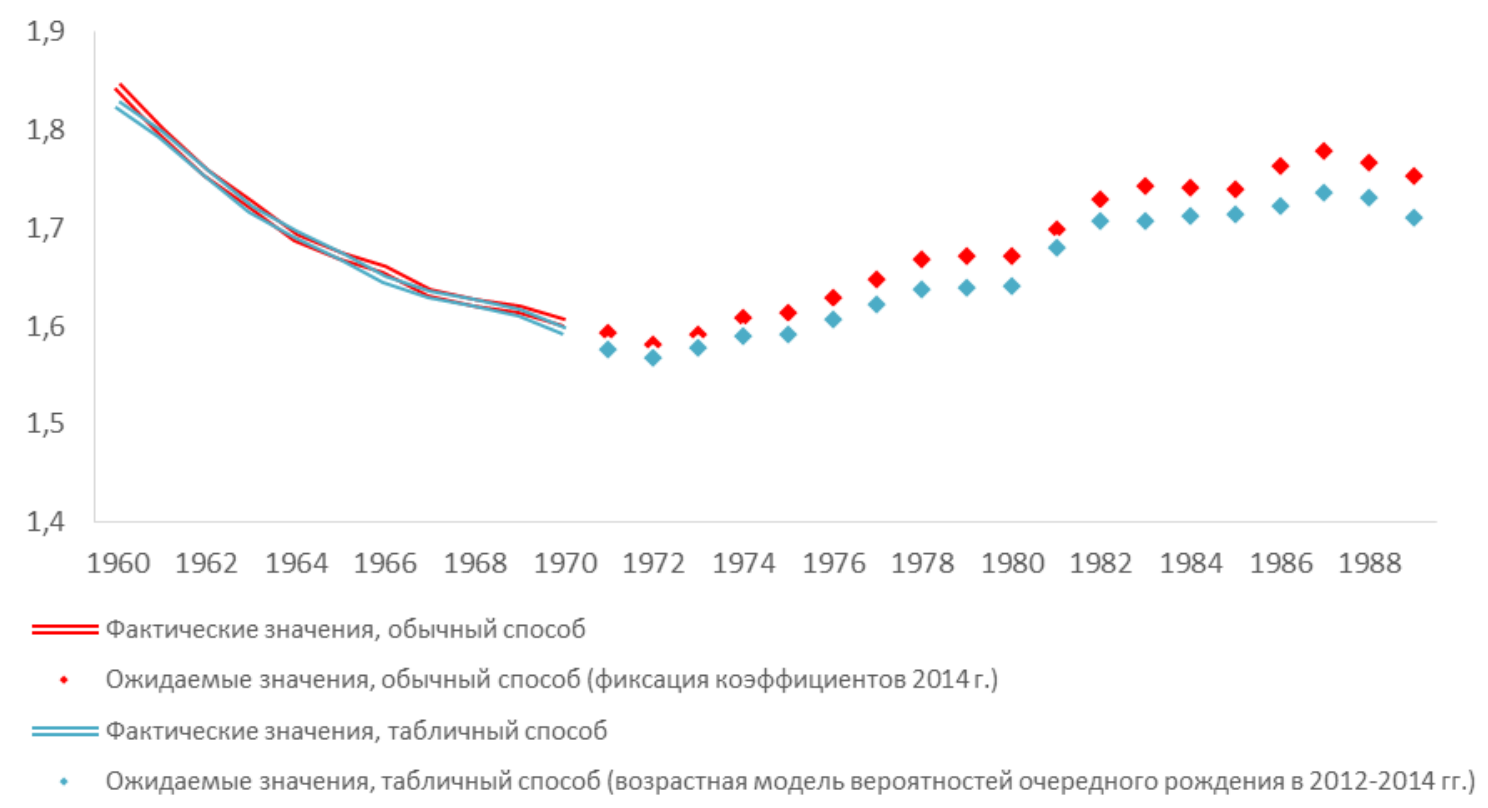

Рисунок 18. Фактические и ожидаемые изменения итоговой величины рождаемости женских поколений 1960-1989 годов рождения, полученные различными способами, Россия, на 1000 женщин

Источник: Расчеты автора.

Перспектива изменения итоговой величины рождаемости для женских поколений 1968-1988 годов рождения представлена на рисунке 18, где отражены оценки, полученные с помощью моделирования возрастной кривой вероятностей рождения очередного ребенка, в сравнении с оценками, полученными более традиционным способом (замораживание возрастных коэффициентов рождаемости на уровне, зафиксированном в 2014 г.). 
Оба способа получения перспективных оценок итоговой рождаемости основаны на частичном использовании характеристик рождаемости для условных поколений и дают приблизительно одни и те же результаты, но второй, более изощренный способ дает чуть более консервативные оценки.

Подводя итоги результатов оценивания перспективного изменения рождаемости реальных поколений, приходим к выводу, что, вероятнее всего, Россия прошла точку исторического минимума уровня рождаемости - менее 1,6 рождений в расчете на одну женщину, достигнутого когортами 1970-х годов рождения. С учетом уровня и структуры рождаемости по очередности рождения, наблюдаемых в самые последние годы, итоговая рождаемость поколений, рожденных в конце 1970-х, будет не намного, но выше, чем у их непосредственных предшественников. Вероятнее всего, медленный рост будет продолжен в поколениях 1980-х годов рождения с тенденцией к стабилизации на уровне 1,7-1,75 рождений на одну женщину.

\section{ПЕРСПЕКТИВЫ ВОСПРОИЗВОДСТВА НАСЕЛЕНИЯ РОССИИ (ВМЕСТО ЗАКЛЮЧЕНИЯ)}

Положительная тенденция последнего десятилетия вселяет определенный оптимизм, но не стоит слишком сильно обольщаться относительными успехами, достигнутыми за полтора десятилетия и в особенности за последние 7 лет. Не исключено, что за кратковременным всплеском репродуктивной активности может последовать компенсаторный спад, вызванный исчерпанием потенциала для дальнейшего роста рождаемости в поколениях, которые под воздействием благоприятной конъюнктуры произвели на свет желанных детей раньше или с укороченными интервалами, чем прежде планировали. В этом случае наши достаточно консервативные оценки перспективного изменения рождаемости, основанные на знаниях сегодняшней текущей ситуации, могут показаться верхом оптимизма.

При анализе рождаемости большое значение имеет оценка ее уровня с точки зрения того, насколько он обеспечивает замещение поколений и влияет на режим воспроизводства населения в целом. Последнее зависит не только от рождаемости, но и от смертности, поэтому необходим показатель, учитывающий оба эти процесса. В качестве такого интегрального показателя обычно используется нетто-коэффициент (чистый коэффициент) воспроизводства населения - число девочек, рожденных в среднем одной женщиной и доживающих до среднего возраста, в котором их родила мать. В этом показателе отражается не общий уровень смертности, а лишь смертность женщин в возрастах от рождения до окончания репродуктивного периода (в качестве верхней возрастной границы репродукции для женщин обычно принимают возраст 50 или 55 лет). В современных условиях ведущим фактором замещения поколений выступает рождаемость, поскольку смертность женщин в детских и молодых возрастах в России уже давно достаточно низка, и ее дальнейшее снижение не способно существенным образом сказываться на интегральных показателях воспроизводства. Об этом и свидетельствуют данные таблицы 11, где представлены основные компоненты расчета нетто-коэффициента воспроизводства населения в России. 
Таблица 11. Компоненты нетто-коэффициента воспроизводства женского поколения, Россия, 1958 - 2014

\begin{tabular}{l|c|c|c|c|c|c}
\hline Годы & $\begin{array}{c}\text { Среднее } \\
\text { число } \\
\text { детей на } \\
\text { одну } \\
\text { женщину }\end{array}$ & $\begin{array}{c}\text { В том числе } \\
\text { девочек (бруто- } \\
\text { коэффициент } \\
\text { воспроизводства) }\end{array}$ & $\begin{array}{c}\text { Средний } \\
\text { возраст } \\
\text { матери, } \\
\text { лет }\end{array}$ & $\begin{array}{c}\text { Вероятность } \\
\text { для девочки } \\
\text { дожить до } \\
\text { среднего } \\
\text { возраста } \\
\text { матери }\end{array}$ & $\begin{array}{c}\text { Нетто- } \\
\text { коэффициент } \\
\text { воспроизводства }\end{array}$ & $\begin{array}{c}\text { Истинный } \\
\text { коэффициент } \\
\text { естественного } \\
\text { прироста } \\
\text { населения, на } \\
1000 *\end{array}$ \\
\hline $1958-1959$ & 2,62 & 1,28 & 27,8 & 0,93 & 1,19 & $+6,0$ \\
$1964-1965$ & 2,14 & 1,05 & 27,6 & 0,93 & 0,97 & $-1,1$ \\
$1968-1969$ & 1,97 & 1,00 & 27,2 & 0,96 & 0,96 & $-1,5$ \\
$1974-1975$ & 1,99 & 0,97 & 26,4 & 0,96 & 0,93 & $-2,7$ \\
$1978-1979$ & 1,90 & 0,92 & 25,9 & 0,96 & 0,88 & $-4,9$ \\
$1984-1985$ & 2,06 & 1,00 & 25,8 & 0,97 & 0,96 & $-1,4$ \\
$1988-1989$ & 2,07 & 1,01 & 25,7 & 0,97 & 0,98 & $-0,8$ \\
$1994-1995$ & 1,37 & 0,66 & 24,7 & 0,97 & 0,64 & $-17,8$ \\
$1998-1999$ & 1,20 & 0,58 & 25,5 & 0,97 & 0,56 & $-22,4$ \\
$2004-2005$ & 1,31 & 0,64 & 26,6 & 0,97 & 0,62 & $-18,6$ \\
$2008-2009$ & 1,52 & 0,74 & 27,3 & 0,98 & 0,72 & $-12,1$ \\
2000 & 1,19 & 0,58 & 25,8 & 0,97 & 0,56 & $-22,2$ \\
2001 & 1,22 & 0,59 & 25,9 & 0,97 & 0,58 & $-21,1$ \\
2002 & 1,29 & 0,62 & 26,1 & 0,97 & 0,61 & $-19,1$ \\
2003 & 1,32 & 0,64 & 26,3 & 0,97 & 0,62 & $-18,1$ \\
2004 & 1,34 & 0,65 & 26,4 & 0,97 & 0,63 & $-17,3$ \\
2005 & 1,29 & 0,63 & 26,5 & 0,97 & 0,61 & $-18,6$ \\
2006 & 1,30 & 0,63 & 26,6 & 0,97 & 0,62 & $-18,2$ \\
2007 & 1,42 & 0,69 & 27,0 & 0,98 & 0,67 & $-14,9$ \\
2008 & 1,50 & 0,73 & 27,2 & 0,98 & 0,71 & $-12,5$ \\
2009 & 1,54 & 0,75 & 27,4 & 0,98 & 0,73 & $-11,4$ \\
2010 & 1,57 & 0,76 & 27,7 & 0,98 & 0,74 & $-10,7$ \\
2011 & 1,58 & 0,77 & 27,7 & 0,98 & 0,75 & $-10,3$ \\
2012 & 1,69 & 0,82 & 27,9 & 0,98 & 0,80 & $-7,9$ \\
2013 & 1,71 & 0,83 & 28,0 & 0,98 & 0,81 & $-7,4$ \\
2014 & 1,75 & 0,85 & 28,1 & 0,98 & 0,83 & $-6,4$ \\
\hline
\end{tabular}

Источник: Опубликованные и неопубликованные данные Росстата, а также расчеты автора на основе общих таблии рождаемости, построенных с учетом смертности для однолетних возрастных групп женщин.

Примечания:

* - Истинный (собственный) коэффициент естественного прироста рассчитан по формуле:

$$
r=\frac{\ln R_{0}}{T}
$$

где $R_{0}$ - нетто-коэффичиент воспроизводства; $T$ - длина поколения или среднее число лет в интервале между рождением условного поколения матерей и их дочерей.

Длина поколения обычно статистически оченивается как средний возраст матери при рождении девочки, дожившей до возраста своей матери. При текущих возрастных функииях рождаемости и смертности оценка длины поколения лишь незначительно отличается от среднего возраста матери при рождении ребенка без учета смертности, представленного в таблище. Так, в 2014 г. в России, по нашей оиенке, длина поколения составляла 28,09 года, а средний возраст матери без учета смертности - 28,12 года.

Подробную ежегодную динамику показателей с 1987 по 2000 год см: [Население России...2006: 271272].

Россия была одной из первых крупных стран, в которых после Второй мировой войны рождаемость опустилась ниже уровня простого замещения поколений. Это 
произошло в далеком 1964 г., и тогда нетто-коэффициент воспроизводства ниже единицы наблюдался только в Венгрии, Латвии, Эстонии, Румынии и Японии. В 1968 г. неттокоэффициент воспроизводства был ниже, чем в России, только в двух республиках СССР Украине и Латвии, а также в Чехии.

Однако вскоре положение в мире изменилось. Процесс снижения рождаемости охватил все промышленно развитые страны, и в 1980-е годы ее уровень практически повсеместно опустился ниже уровня простого замещения поколений.

В 2011-2014 гг. не было ни одной развитой страны, в которой значение этого показателя находилось бы на уровне простого воспроизводства населения ${ }^{4}$. Максимально близко приближаются к границе простого воспроизводства Ирландия, Исландия, Новая Зеландия, Франция - нетто-коэффициент в пределах 0,95-0,99. В то же время в странах Южной, Восточной и Центральной Европы, в Восточной Азии так же, как и в России, режим воспроизводства далек от границы простого замещения поколений.

Наблюдаемая в 2014 г. в России величина нетто-коэффициента воспроизводства $(0,83)$ указывает на то, что, с учетом смертности, текущий уровень рождаемости обеспечивает замещение поколений нынешних матерей лишь на 83\%. Поэтому если на протяжении двух-трех десятилетий текущие (т.е. наблюдаемые сегодня) режимы рождаемости и смертности не будут меняться, то можно ожидать, что каждое последующее дочернее поколение будет меньше предыдущего на 17\%. В таком стабильном (т.е. имеющем неизменный режим воспроизводства) населении ежегодный коэффициент естественного прироста (так называемый «истинный» или «собственный» коэффициент естественного прироста, очищенный от влияния возрастной структуры) станет отрицательным на уровне $-6,4$ на 1000 населения. В этом случае численность населения страны, закрытой для миграции, будет сокращаться ежегодно на 0,64\% (таблица 11).

В 2014 г. фактический коэффициент естественного прироста для всего населения России составил 0,2 промилле, т.е. едва отличался от нуля в положительную сторону (в городской местности - 0,4, в сельской $-0,0$ на 1000 населения). Причина расхождения между «истинным» и фактическим коэффициентами объясняется тем, что фактическая возрастная структура населения России сильно отличается от структуры модельного стабильного населения, соответствующего сегодняшним уровням рождаемости и смертности. Сегодня возрастной состав населения России благоприятствует тому, чтобы население не слишком быстро сокращалось. Но если наблюдаемый режим замещения поколений будет сохраняться продолжительное время, то фактический коэффициент естественного прироста станет приближаться к истинному, что будет означать усиливающуюся естественную убыль и городского, и, тем более, сельского населения. Существенное увеличение рождаемости условного поколения в 2007-2014 гг. и суммарно за весь период с 1999 г. (после достижения ее исторического минимума) не могло не

\footnotetext{
${ }^{4}$ Мы оставляем в стороне специфический случай Израиля, который по уровню своего экономического развития безусловно является развитой страной. В то же время в силу специфических исторических и социокультурных условий в этой стране уже не одно десятилетие сохраняется достаточной высокий КСР - 3 и более рождений на одну женщину, что гарантирует поддержание величины нетто-коэффициента существенно превышающей уровень простого воспроизводства - 1,4 и выше.
} 
сказаться положительно на интегральных показателях режима воспроизводства населения, которые тоже относятся к условному поколению. В то же время путь, который должен быть пройден Россией, чтобы выйти из зоны суженного режима демографического воспроизводства, еще долог.

Хотя российские показатели смертности в целом далеки от идеала, которым для России служат другие развитые страны, в детском и в материнском возрастах разрыв невелик, а потому невелики и имеющиеся резервы с точки зрения показателей воспроизводства населения. Если в России 98\% девочек доживает до среднего возраста матери, то лучшие показатели в мире - 99\%. Даже если предположить, что ни одна девочка, родившаяся в 2014 г., не умрет и сможет (и захочет) стать матерью, то при нынешнем уровне рождаемости это смогло бы всего лишь увеличить нетто-коэффициент воспроизводства до уровня брутто-коэффициента (т.е. с наблюдаемого 0,83 до 0,85). Принципиальным образом улучшить ситуацию с воспроизводством населения может только повышение рождаемости у ныне живущих поколений и отчасти иммиграция, если в среде мигрантов рождаемость будет выше, чем у проживающих сегодня на территории России.

Впрочем, воздействие миграции на число рождений не ограничивается более высокой интенсивностью деторождения в семьях мигрантов ${ }^{5}$. Мигрируют в большинстве своем молодые люди, что благотворно сказывается на возрастной структуре населения, а это в свою очередь увеличивает число браков и рождений и, соответственно, тормозит переход к устойчивому отрицательному естественному приросту в развитых странах. В то же время возможность перехода к устойчивому отрицательному балансу рождений и смертей не только в России, но и в подавляющем большинстве развитых стран следует рассматривать как весьма вероятную угрозу, о чем предупреждают величина неттокоэффициента воспроизводства меньше единицы и величина истинного коэффициента естественного прироста населения ниже нуля, сохраняющиеся в этих странах с середины 1970-х годов.

\section{ЛИТЕРАТУРА}

Бирюкова С.С. (2012). Возможности оценки вклада мигрантов в рождаемость и смертность на основе данных текущей статистики населения в России // SPERO. Социальная политика: экспертиза, рекомендации, обзоры. 6: 79-94.

Демографическая модернизация России, 1900-2000 (2006) / Под ред. А.Г. Вишневского. М.: Новое издательство. 608 с.

Захаров С.В., С.В. Сурков (2009). Миграционный опыт и рождаемость в послевоенных поколениях россиян // Родители и дети, мужчины и женщины в семье и обществе. Сб. аналитических статей. Вып. 2 / Научн. ред. С.В. Захаров, Т.М. Малева, О.В. Синявская. М.: НИСП: 45-118.

\footnotetext{
${ }^{5}$ Различия в уровне рождаемости у мигрантов и немигрантов в России нами рассматривались ранее: [Захаров, Сурков 2009; Население России... 2010: 111-132]. См. также: [Бирюкова 2012].
} 
Население России 2002 (2004). Десятый ежегодный демографический доклад / Отв. ред. А.Г. Вишневский. М.: Издательство КДУ. 224 с.

Население России 2003-2004 (2006). Одиннадцатый-двенадцатый ежегодный демографический доклад / Отв. ред. А.Г. Вишневский. М.: Наука. 356 с.

Население России 2008 (2010). Шестнадцатый ежегодный демографический доклад / Отв. ред. А.Г. Вишневский. М.: Изд. дом Высшей школы экономики. 352 с.

Население России 2012 (2014). Двадцатый ежегодный демографический доклад / Отв. ред. А.Г. Вишневский. М.: Изд. дом Высшей школы экономики. 412 с.

Biryukova S.S., A.O. Tyndik (2015). Prevalence and determinants of childlessness in Russia and Moscow // Genus. 71(1): 1-22

HFD (2016). The Human Fertility Database. Max Planck Institute for Demographic Research (Germany) and Vienna Institute of Demography (Austria). URL: www.humanfertility.org (данные загружены 02.01.2016). 


\title{
MODEST DEMOGRAPHIC RESULTS OF THE PRONATALIST FAMILY POLICY IN THE CONTEXT OF LONG-TERM EVOLUTION OF FERTILITY IN RUSSIA. Part 2
}

\section{SERGEI ZAKHAROV}

\begin{abstract}
The point of view of the extraordinary growth of fertility in Russia is widespread in the Russian expert community and media space. This increase is believed to be indicative of the positive results of the special financial measures taken by the State after 2006 in order to stimulate the birth rate.

Do demographers have strong bases to support the increased optimism that demonstrated today by politicians and administrators of different levels? According to the author, there are some positive developments, but their significance is quite insufficient to face the pink glasses on the future of Russian fertility and reproduction of population of the country.
\end{abstract}

With this paper, the author continues his previous long-term research in the field of in-depth demographic analysis of Russian fertility involving the latest official statistical data for 2014. The paper provides an overview of the trends of key fertility indicators in a few decades, as well as develops some methodological issues of the cohort fertility analysis in order to obtain more reliable projections.

The article consists of two interrelated parts.

In the first part, presented in the previous issue, the author examines period fertility indicators (for calendar years), taking into account the latest changes in the structural characteristics of the Russian model of fertility that have occurred over the past several decades.

In the second part of the article, which presented in this issue of the Journal, the author analyses cohort fertility indicators of generations of women, whose the actual and the expected reproductive activity has occurring in the second half of the XX - the first decades of the XXI century.

Key words: fertility, birth order, period fertility, cohort fertility, fertility projections, demographic policy, pronatalist family policy in Russia.

SERGEI V. ZAKHARov (szakharov@hse.ru), NATIONAL RESEARCH University HighER School Of EconOMics, RUSSIA.

THE RESULTS OF THE PROJECT "DEMOGRAPHIC DEVELOPMENT IN RUSSIA IN 2005-2015 IN THE CONTEXT OF LONG-TERM TRENDS", CARRIED OUT WITHIN THE FRAMEWORK OF THE BASIC RESEARCH PROGRAM AT THE NATIONAL RESEARCH UNIVERSITY HIGHER SCHOOL OF ECONOMICS (HSE) IN 2016, ARE PRESENTED IN THIS PAPER.

DATE RECEIVED: APRIL 2016.

\section{REFERENCES}

Birukova S.S. (2012). Vozmozhnosti otsenki vklada migrantov v rozhdaemost' i smertnost' na osnove dannykh tekushchey statistiki naseleniya $\mathrm{v}$ Rossii [Estimates of migrants' contribution to birth and death rates in Russia based on official vital statistics] // SPERO. Social policy: expertise, recommendations, overviews. №16 (Spring-summer): 79-94.

Biryukova S.S., A.O. Tyndik (2015). Prevalence and determinants of childlessness in Russia and Moscow // Genus. 71(1): 1-22.

Demograficheskaya modernizatsiya Rosii, 1900-2000 [Demographic modernization of Russia, 1900-2000] (2006) / A.G. Vishnevsky, ed. Moskva: Novoe izdatel'stvo. 608 p. 
HFD (2016). The Human Fertility Database. Max Planck Institute for Demographic Research (Germany) and Vienna Institute of Demography (Austria). URL: www.humanfertility.org (data downloaded on 02.01.2016).

Naselenie Rossii 2002 [Population of Russia 2002] (2004). Desyatyy ezhegodnyy demograficheskiy doklad [Tenth annual demographic report] / A.G. Vishnevsky, ed. Moskva: Izdatelstvo KDU. 224 p.

Naselenie Rossii 2003-2004 [Population of Russia 2003-2004] (2006). Odinnadtsatyydvenadtsatyy ezhegodnyy demograficheskiy doklad [Eleventh-twelfth annual demographic report] / A.G. Vishnevsky, ed. Moskva: Nauka. 356 p.

Naselenie Rossii 2008 [Population of Russia 2008] (2010). Shestnadtsatyy ezhegodnyy demograficheskiy doklad [Sixteenth annual demographic report] / A.G. Vishnevsky, ed. Moskva: Izd. dom Vysshey shkoly ekonomiki. 352 p.

Naselenie Rossii 2012 [Population of Russia 2012] (2014). Dvadtsatyy ezhegodnyy demograficheskiy doklad [Twentieth annual demographic report] / A.G. Vishnevsky, ed. Moskva: Izd. dom Vysshey shkoly ekonomiki. 412 p.

Zakharov S.V., S.V. Surkov (2009). Migratsionnyy opyt i rozhdaemost' v poslevoennykh pokoleniyakh rossiyan [Migration experience and fertility in postwar generations in Russia] // Roditeli i deti, muzhchiny i zhenshchiny v sem'e i obshchestve. Sb. analiticheskikh statey. Vyp. 2 [Parents and children, men and women in family and society. Issue 2] / S.V. Zakharov, T.M. Maleva, O.V. Sinyavskaya, eds. Moskva: Independent institute for social policy: 45-118. 